\title{
Effect of Rare Earth Metals on the Properties of Zn-20Sn High- Temperature Lead-Free Solder
}

\author{
JUN TIAN, $, 1,2,3$ CHUNFU HONG, ${ }^{2,3}$ LIHUA HONG, ${ }^{2,3}$ XIAOHUI YAN, ${ }^{2,3}$ \\ and PINQIANG DAI ${ }^{1,2,3,4}$
}

\begin{abstract}
1.-School of Materials Science and Engineering, Fuzhou University, Fuzhou, China. 2.-School of Materials Science and Engineering, Fujian University of Technology, Fuzhou, China. 3.-Fujian Provincial Key Laboratory of Advanced Materials Processing and Application, Fuzhou, China. 4.—e-mail: pqdai@126.com
\end{abstract}

\begin{abstract}
Cerium-lanthanum mixed rare earth (RE) (0.5 wt.\%) was added to $\mathrm{Zn}-20 \mathrm{Sn}$ high-temperature lead-free solder to study the effect of $\mathrm{RE}$ on the solder properties. The $\mathrm{Zn}-20 \mathrm{Sn}-0.5 \mathrm{RE}$ solder has a better corrosion resistance than that of $\mathrm{Zn}-20 \mathrm{Sn}$ alloy. $\mathrm{RE}$ addition increases the $\gamma-\mathrm{Cu}_{5} \mathrm{Zn}_{8}$ layer thickness, promotes growth of a $\varepsilon-\mathrm{CuZn}_{5}$ layer shaped like bamboo shoots, and increases the roughness of the $\varepsilon-\mathrm{CuZn}_{5}$ layer, which increases the shear strength of the solder joints. Compared with the $\mathrm{Zn}-20 \mathrm{Sn}$ alloy, the creep resistance of the $\mathrm{Zn}$ 20Sn-0.5RE solder was improved after soldering. The indentation hardness increases in an order of Zn-20Sn-0.5RE solder, Zn-20Sn solder, $\varepsilon-\mathrm{CuZn}_{5}$ layer, and $\gamma-\mathrm{Cu}_{5} \mathrm{Zn}_{8}$ layer.
\end{abstract}

Key words: Zn-20Sn alloy, high-temperature lead-free solder, corrosion resistance, interfacial reaction, shear strength, nanoindentation

\section{INTRODUCTION}

High-lead solders, such as $95 \mathrm{~Pb}-5 \mathrm{Sn}$ and $90 \mathrm{~Pb}-$ $10 \mathrm{Sn}$, have been applied commonly in high-temperature electronic packaging. However, lead is toxic to human beings, and its application is restricted globally. Because a suitable alternative material has not been found, high-lead solders are allowed in some cases. Thus, the development of a new hightemperature lead-free solder that can replace traditional high-lead solder and other lead-free interconnect processes has become an urgent requirement in electronics packaging. ${ }^{1}$

Zn-Sn-based solder does not generate intermetallic compounds (IMCs) and has advantages of an appropriate melting temperature range, better plasticity, better thermal/electrical conductivity and low cost, so it is an alloy that is most likely to replace high-lead solders. ${ }^{2-5}$ To solve the problems of the poor wettability and poor oxidation resistance of the

(Received July 16, 2018; accepted December 29, 2018;

published online January 8, 2019)
Zn-Sn-based solder, an alloying method may be used to improve its properties. 6 When a small amount of rare earth (RE) is added, the surface tension of $\mathrm{Sn}-\mathrm{Ag}-\mathrm{Cu}$ solder may be reduced during soldering, which promotes solder wetting on the substrate. ${ }^{7}$ In addition, it is found that the solder wettability could be improved by the addition of 0.5 wt.\% cerium-lanthanum mixed RE in $\mathrm{Zn}-20 \mathrm{Sn}{ }^{8}$ However, the effect of $\mathrm{RE}$ on the performance of solder joints made of $\mathrm{Zn}-20 \mathrm{Sn}$ alloy has not been reported. In present paper, the mechanical behavior, microstructure, wettability, and corrosion resistance of solder joints of Zn-20Sn and Zn-20Sn-0.5RE solders were investigated, and the effect of the RE on the IMC layer at solder/Cu interface was investigated. The results provide a reference for the development of new high-temperature lead-free solders.

\section{EXPERIMENTAL PROCEDURES}

$\mathrm{RE}$ elements $(0.5 \mathrm{wt} . \%)$ were added to $\mathrm{Zn}-20 \mathrm{Sn}$ alloy. Zn particles and Sn particles with a purity of more than 99.9 wt.\% were selected. The weight 
ratio of $\mathrm{Ce}$ and La was $65 / 35$ in the mixed $\mathrm{RE}$ blocks. The mass fraction of Ce and La exceeded $99 \%$ in the total mass of REs. The alloys were prepared by the method as described in the literature. ${ }^{8}$

A wettability test was conducted at five different temperatures $\left(400^{\circ} \mathrm{C}, 410^{\circ} \mathrm{C}, 420^{\circ} \mathrm{C}, 430^{\circ} \mathrm{C}\right.$, and $440^{\circ} \mathrm{C}$ ) using a wetting balance (RHESCA 5200TN, made in Japan). A copper sheet (30 $\mathrm{mm} \times 5 \mathrm{~mm} \times$ $0.3 \mathrm{~mm}$ ) was soaked in absolute ethanol and washed ultrasonically for $5 \mathrm{~min}$. The copper sheet was dipped into molten solder with an immersion rate of $5 \mathrm{~mm} / \mathrm{s}$. After being dipped to a depth of $3 \mathrm{~mm}$ for $5 \mathrm{~s}$, then the copper sheet was lifted up with rate of $5 \mathrm{~mm} / \mathrm{s}$. The wetting time is given on the JIS Z 3198.

Polarization curves for the solder alloy were measured by using an electrochemical tester (Autolab 302). Sodium-chloride aqueous solution (5\%) was used as a corrosive medium. The reference electrode was a saturated calomel electrode and the auxiliary electrode was a platinum electrode. The test temperature was $20^{\circ} \mathrm{C}$. The potential scanning range was $-0.1 \mathrm{~V}$ to $0.1 \mathrm{~V}$. The scanning rate was $0.001 \mathrm{~V} / \mathrm{s}$.

The $\mathrm{Cu}$ substrate used for shear strength test was $50 \mathrm{~mm} \times 10 \mathrm{~mm} \times 1 \mathrm{~mm}$ and the lap area was $10 \mathrm{~mm} \times 5 \mathrm{~mm}$. After the $\mathrm{Cu}$ substrate was polished, it was soaked in $10 \%$ hydrochloric acid solution for $10 \mathrm{~s}$, washed with absolute ethanol, and blown dry. Solder pieces $(10 \mathrm{~mm} \times 5 \mathrm{~mm} \times$ $0.15 \mathrm{~mm}$ ) were coated with flux, placed between two $\mathrm{Cu}$ substrates, and then heated in furnace at $440^{\circ} \mathrm{C}$ for $300 \mathrm{~s}$. As contrast, the $\mathrm{Pb}-5 \mathrm{Sn}$ alloy is heated at $350^{\circ} \mathrm{C}$ for $300 \mathrm{~s}$.

The pieces were removed with air-cooling. The loading speed of the electronic universal testing machine was $1 \mathrm{~mm} / \mathrm{min}$. The shear fracture area was measured by using an Auto CAD. The data for each sample were an average of three samples.

After spreading test, which was conducted at soldering temperature of $440^{\circ} \mathrm{C}$ with soldering time of $300 \mathrm{~s}$, the spreading specimen was cut down in center. Half of the sample was used for microstructure observation by using cold inlay processing and mechanical polishing. For the other half of the sample, solder surface was polished first until it was close to the $\mathrm{Cu}$ substrate. Then, it was placed in $10 \mathrm{vol} . \%$ hydrochloric acid/alcohol solution, and deep etching was performed on the solder to expose the interfacial IMC. The interface microstructure was observed by using Hitachi S-3400 N scanning electron microscopy (SEM). Compositional analysis was performed by using a QUANTAX EDS and the interfacial IMC thickness was measured.

Thickness of the interfacial IMCs was measured for each layer. Thickness of the ${ }_{\varepsilon}-\mathrm{CuZn}_{5}$ was calculated by using a software. Its thickness was measured and calculated according to:

$$
H=\frac{A}{L}
$$

where $H$ is the thickness of the IMC layer, $A$ is the area of the IMC layer, and $L$ is the length of the IMC layer for the selected region. According to the literature,${ }^{9}$ the roughness was calculated as:

$$
R_{\mathrm{rms}}=\sqrt{\frac{1}{N} \sum_{i=1}^{N} Z_{i}^{2}}
$$

where $R_{\text {rms }}$ is the roughness ( $\left.\mu \mathrm{m}\right), N$ is the number of measurement points in the selected area, and $Z_{i}$ is the distance from IMC peak value of the measurement area to the measurement baseline $(\mu \mathrm{m})$. The thickness of ten points of the center area at the interface was measured. Then, the IMC roughness at the interface was obtained by the measurement and calculation.

Indentation hardness and creep properties of the solders were measured by using a TI-Premier nanoindenter. The constant applied load was $6 \mathrm{mN}$. The applied load rate was $100 \mu \mathrm{N} / \mathrm{s}$. The duration time was $120 \mathrm{~s}$. The unloading time was $60 \mathrm{~s}$.

\section{EXPERIMENTAL RESULTS AND DISCUSSION}

\section{Wettability}

The wettability time of the Zn-20Sn-0.5RE and $\mathrm{Zn}-20 \mathrm{Sn}$ solder alloys on $\mathrm{Cu}$ substrate at various soldering temperature is shown in Fig. 1.

It can be seen that the wetting time of the $\mathrm{Zn}$ 20Sn-0.5RE alloy on the $\mathrm{Cu}$ sheet decreased gradually with an increase of soldering temperature. The wetting time was the shortest at $440^{\circ} \mathrm{C}$ and the solder wettability was the best. When the soldering temperature was $400^{\circ} \mathrm{C}$, the wetting time increased by the addition of $0.5 \% \mathrm{RE}$ and the wetting effect was poor. The addition of RE has almost no effect on the wetting time at temperature of $410-440^{\circ} \mathrm{C}$.

The wetting time was strongly dependent on the interface reaction occurred between the solder and substrate. ${ }^{10}$ It could be inferred from the wetting

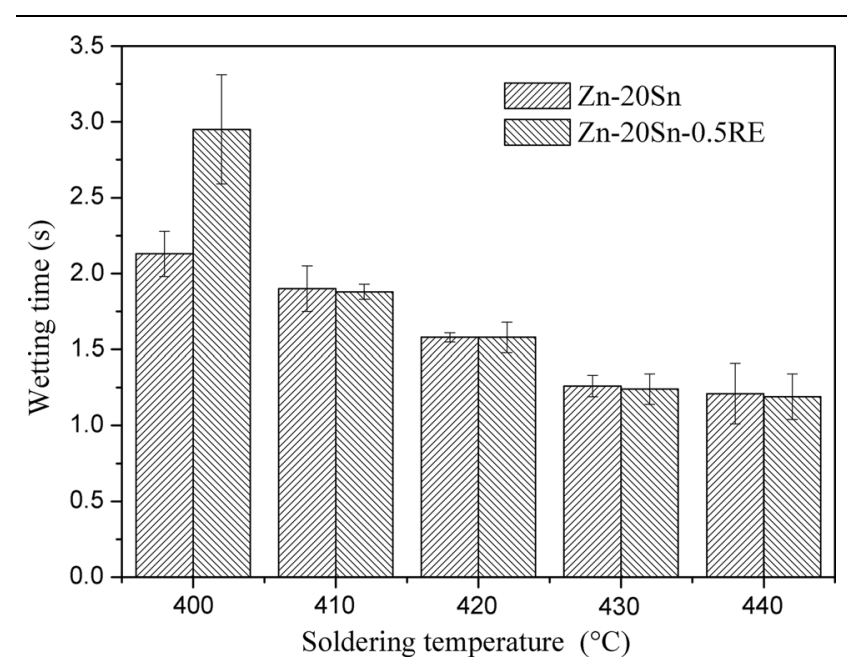

Fig. 1. Relationship between soldering temperature and wettability time. 
time that the reaction rate increased with an increase in soldering temperature. In order to obtain a better wettability, the soldering temperature should exceed $430^{\circ} \mathrm{C}$.

\section{Electrochemical Corrosion}

Polarization curves of the Zn-20Sn and Zn-20Sn$0.5 \mathrm{RE}$ in $5 \% \mathrm{NaCl}$ solution are shown in Fig. 2. The corrosion voltage and corrosion current density are obtained by the curve fitting, as shown in Table I.

In Table I, Zn-20Sn-0.5RE alloy has a smaller corrosion current density and higher corrosion voltage. It shows the electrochemical corrosion resistance property of $\mathrm{Zn}-20 \mathrm{Sn}-0.5 \mathrm{RE}$ alloy is better than that of $\mathrm{Zn}-20 \mathrm{Sn}$ alloy. In addition, previous work indicates that adding small amount of $\mathrm{RE}(\mathrm{Ce}$, $\mathrm{Er}$ and $\mathrm{Y}$ ) into $\mathrm{Zn}-5 \mathrm{Al}$ alloy can obviously improve the corrosion resistance of the alloy. This behaviour may be ascribed to improved protective properties of the corrosion products layer, which acts as an effective barrier against corrosion progress. ${ }^{11}$ As REs may improve protective properties of the corrosion products layer, thus enhances the corrosion resistance of the $\mathrm{Zn}-20 \mathrm{Sn}$ alloy.

\section{Interfacial IMC}

Microstructures of the solder joint at a soldering temperature of $440^{\circ} \mathrm{C}$ and a soldering time of $300 \mathrm{~s}$ are shown in Fig. 3. The $\mathrm{Zn}$-Sn binary phase

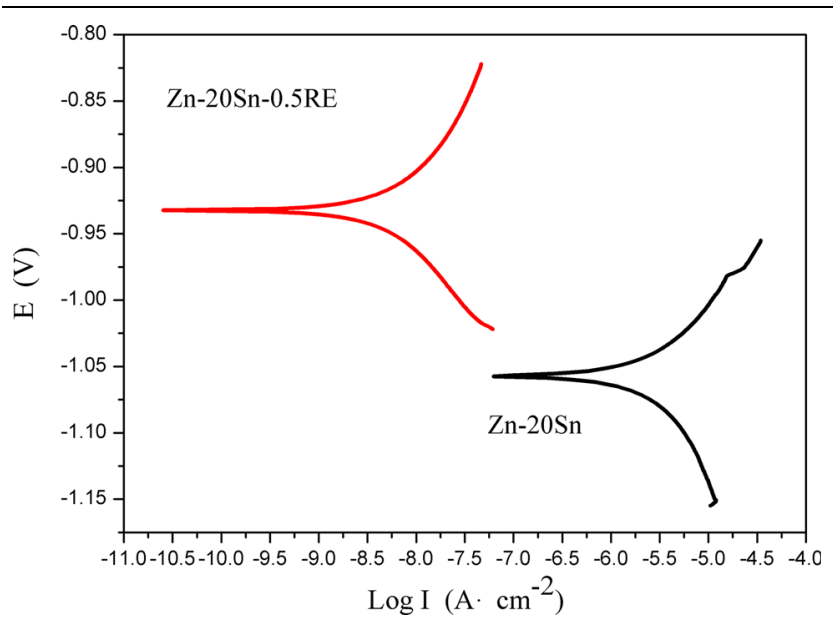

Fig. 2. Polarization curves of solder alloys.

Table I. Electrochemical corrosion data of solder alloys

\begin{tabular}{|c|c|c|}
\hline Solder & $\begin{array}{c}\text { Corrosion } \\
\text { voltage }(\mathbf{V})\end{array}$ & $\begin{array}{c}\text { Corrosion current den- } \\
\text { sity }\left(\mu \mathrm{A} / \mathrm{cm}^{2}\right)\end{array}$ \\
\hline $\mathrm{Zn}-20 \mathrm{Sn}$ & -1.051 & 2.904 \\
\hline $\begin{array}{l}\mathrm{Zn}-20 \mathrm{Sn}- \\
0.5 \mathrm{RE}\end{array}$ & -0.941 & 0.006 \\
\hline
\end{tabular}

diagram shows that the microstructure of $\mathrm{Zn}-20 \mathrm{Sn}$ solder consists of primary $\alpha-\mathrm{Zn}$ and eutectic structure $(\alpha-\mathrm{Zn}+\beta$-Sn $)$, as shown in Fig. 3a. The dissolution speed of the $\mathrm{Cu}$ substrate into liquid solder is rapid and it diffuses rapidly deep into the liquid phase, which result in the formation of interfacial IMC layer. With reference to the research on the interfacial reaction between $\mathrm{Zn}-\mathrm{Sn}$ solder and the $\mathrm{Cu}$ substrate, ${ }^{2-5}$ the IMC layer at the interface consists of three parts: the bamboo-shoot-like $\varepsilon$ $\mathrm{CuZn}_{5}$ near the solder side, the flat-layer-like $\beta^{\prime}$ $\mathrm{CuZn}$ near the $\mathrm{Cu}$ side, and the flat-layer-like $\gamma$ $\mathrm{Cu}_{5} \mathrm{Zn}_{8}$ in the middle. The $\beta^{\prime}$-CuZn layer thickness is very thin and is usually less than $1 \mu \mathrm{m}$, which is often ignored in the literature. ${ }^{2}$ As confirmed by EDS, $\varepsilon-\mathrm{CuZn}_{5}$ of dendritic growth may be isolated existing in the solder. Actually, the isolated $\varepsilon-\mathrm{CuZn}_{5}$ was some cross-section of the bamboo-shoot-like $\varepsilon$ $\mathrm{CuZn}_{5}$ that grows from the interface as shown in Fig. 3b.

After adding 0.5 wt.\% RE, the compound containing REs is shown in Fig. 3c. XRD fails to detect this compound because of its low content. $\mathrm{RE}$ addition promotes the growth of the $\varepsilon-\mathrm{CuZn}_{5}$ and $\gamma-\mathrm{Cu}_{5} \mathrm{Zn}_{8}$ layer at the interface, especially the bamboo-shootlike growth of $\varepsilon-\mathrm{CuZn}_{5}$, as shown in Fig. $3 \mathrm{~d}$.

Figure 3d shows that the bamboo-shoot-like growth of the $\varepsilon-\mathrm{CuZn}_{5}$ of the IMC layer at the solder interface with 0.5 wt.\% RE addition in the alloy is more intense, that is, $\mathrm{Cu}$ diffused deeply into the solder. The interfacial roughness of the $\varepsilon-\mathrm{CuZn}_{5}$ layer of $\mathrm{Zn}-20 \mathrm{Sn}$ alloy is 1.44, and the interfacial roughness of the $\varepsilon-\mathrm{CuZn}_{5}$ layer of the $\mathrm{Zn}-20 \mathrm{Sn}$ $0.5 \mathrm{RE}$ alloy is 7.09 . After 0.5 wt.\% $\mathrm{RE}$ addition, the $\gamma-\mathrm{Cu}_{5} \mathrm{Zn}_{8}$ layer thickness of the IMC increases by $12.4 \%$, whereas the thickness of the $\varepsilon-\mathrm{CuZn}_{5}$ layer of the IMC increases by $30 \%$. The roughness of the $\varepsilon$ $\mathrm{CuZn}_{5}$ layer is increased by $392.4 \%$.

Research results on middle-temperature solders show that when the wetting of liquid Sn-based solder and $\mathrm{Cu}$ substrate occurred, the following relationship of force equilibrium must be satisfied at the grain boundary during IMC grain growth at the interface between the solder and $\mathrm{Cu}^{9,12}$ In the present work, the equilibrium of the force at the grain boundary of $\mathrm{CuZn}_{5}$ is studied.

$$
\gamma_{\mathrm{gb}}=2 \gamma_{\mathrm{il}} \cos \theta_{\mathrm{il}}
$$

where $\gamma_{\mathrm{gb}}$ is the grain boundary energy of the $\mathrm{CuZn}_{5}, \gamma_{\mathrm{il}}$ is the interfacial energy between the $\mathrm{CuZn}_{5}$ grains and liquid solder at the interface, and $\theta_{\text {il }}$ is the equilibrium half-angle of the $\mathrm{CuZn}_{5}$ grains at the interface.

A schematic diagram of the force-equilibrium condition at grain boundary in liquid-phase reaction is shown in Fig. 4.

The value of the equilibrium half-angle $\theta_{\mathrm{il}}$ at grain boundaries of the $\mathrm{CuZn}_{5}$ depends mainly on the interfacial energy, $\gamma_{\mathrm{il}}$ between the $\mathrm{CuZn}_{5}$ grain and liquid solder. $\gamma_{\mathrm{il}}$ is affected by the solder 

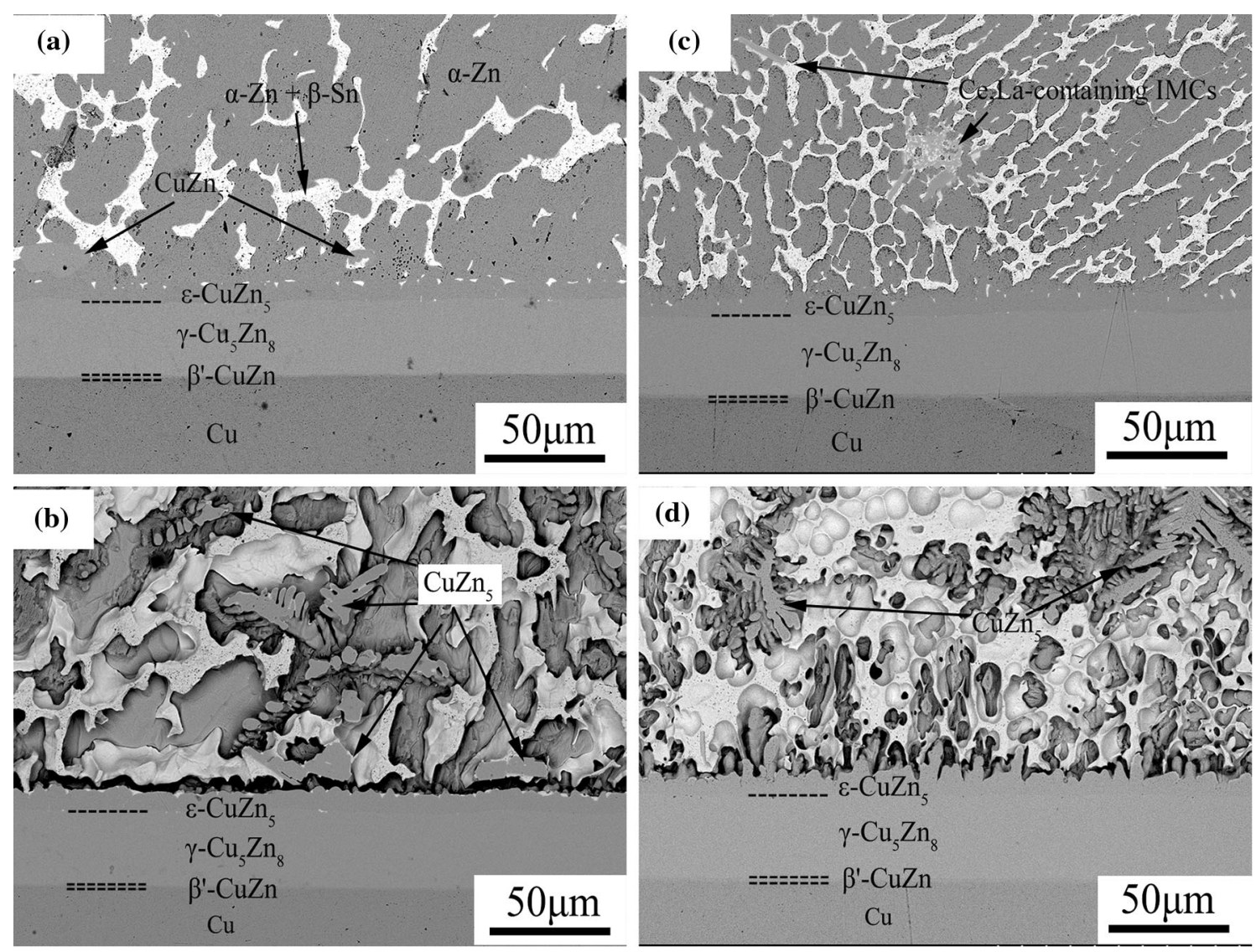

Fig. 3. Cross-sectional SEM micrographs of the interface between solder alloys and Cu substrate: (a) Zn-20Sn, (c) Zn-20Sn-0.5RE, SEM micrographs of the interface between solder alloys and Cu substrate after etching. (b) Zn-20Sn, (d) Zn-20Sn-0.5RE.

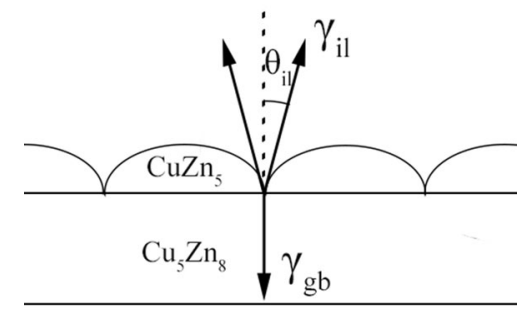

Fig. 4. Schematic diagram of force-equilibrium condition at grain boundary in liquid-phase reaction.

composition and reaction temperature. ${ }^{9}$ In this study, the reaction temperature was the same, whereas the solder composition was different. After $\mathrm{RE}$ addition, the bamboo-shoot-like growth of the $\varepsilon$ $\mathrm{CuZn}_{5}$ was strong and the equilibrium half-angle decreased. Thus, the interfacial energy of the $\gamma_{\mathrm{il}}$ between the $\varepsilon-\mathrm{CuZn}_{5}$ grains and liquid solder decreased. $\mathrm{RE}$ addition resulted in a decreased interfacial energy between the solid and liquid,

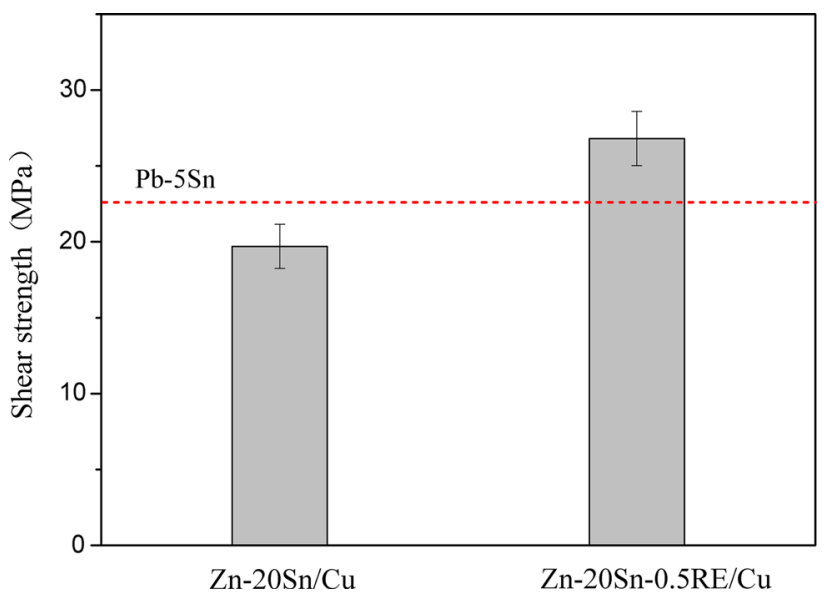

Fig. 5. Shear strength of soldered joints.

which resulted in a strong growth of bamboo-shootlike $\varepsilon-\mathrm{CuZn} \mathrm{n}_{5}$.

Earlier, it was indicated that the increase in IMC roughness at the interface of the $\mathrm{Sn}-\mathrm{Pb}$ solder/Cu leads to a decrease in crack resistance with highspeed propagation after the solder joints have been heated for a long time, which is not conducive to the wetting and spreading of solder on the substrate. ${ }^{13}$ 
In this study, a similar results are obtained. That is the IMC roughness of solder/Cu interface has no influence on the spreading area of the test solders, even the IMC roughness of $\mathrm{Zn}-20 \mathrm{Sn}-0.5 \mathrm{RE} / \mathrm{Cu}$ interface is larger than that of $\mathrm{Zn}-20 \mathrm{Sn}$.

\section{Shear Strength}

The effect of $0.5 \mathrm{wt} . \% \mathrm{RE}$ addition on the shear strength of soldered joints is shown in Fig. 5. The shear strength of the solder joint of the Zn-20Sn solder alloy is about $20 \mathrm{MPa}$, which is lower than that of the solder joint of the Pb-5Sn solder alloy (23.1 MPa). However, the shear strength $(26.8 \mathrm{MPa})$ of the $\mathrm{Zn}-20 \mathrm{Sn}-0.5 \mathrm{RE}$ solder joint is higher than that of the $\mathrm{Pb}-5 \mathrm{Sn}$, and the solder joint exhibit an excellent mechanical property.

It may be mentioned that the shear strength of $\mathrm{Zn}-20 \mathrm{Sn} / \mathrm{Cu}$ joint is lower than that given in the literature (about $31-33 \mathrm{MPa}){ }^{14}$ This is related to the heating temperature and holding time during soldering. In order to obtain better wettability, the soldering joint was heated at $440^{\circ} \mathrm{C}$ for $300 \mathrm{~s}$. The shear strength of $\mathrm{Zn}-20 \mathrm{Sn} / \mathrm{Cu}$ was lower because of the thickening of IMC layer at the interface.

The thickness and morphology of IMC at the interface correlate well with the strength of the solder joint. After RE addition, thickness of the $\gamma$ $\mathrm{Cu}_{5} \mathrm{Zn}_{8}$ and $\varepsilon-\mathrm{CuZn}_{5}$ layer was increased. The IMC roughness at the interface increased. The $\varepsilon-\mathrm{CuZn}_{5}$ with a bamboo-shoot-like structure is embedded into the solder like numerous nails, which improves the bonding strength of the solder and substrate. ${ }^{15}$ However, if the flat $\gamma-\mathrm{Cu}_{5} \mathrm{Zn}_{8}$ layer is too thick at the interface, the shear strength of the soldered joints may decrease because of its high brittleness.

\section{Micromechanical Behavior of Interface}

The nano-indentation technique has been used extensively to characterize the mechanical properties of the local area and creep properties of solder joints. ${ }^{16-18}$ Two layers of IMCs of $\varepsilon-\mathrm{CuZn}_{5}$ and $\gamma$ $\mathrm{Cu}_{5} \mathrm{Zn}_{8}$ formed between the solder alloy and the $\mathrm{Cu}$ substrate. Using the nano-indentation test, the indentation hardness of the IMC and solders are obtained. Load-displacement curves of each phase at the interface and the solder alloys are shown in Fig. 6.

Figure 6 shows that the $\gamma-\mathrm{Cu}_{5} \mathrm{Zn}_{8}$ is the hardest phase in the interfaces. With the predetermined load of $6 \mathrm{mN}$, the maximum indentation depth of the $\gamma-\mathrm{Cu}_{5} \mathrm{Zn}_{8}$ phase is the shallowest in all the phases, followed by $\varepsilon-\mathrm{CuZn}_{5}$. The solder hardness is smaller. The hardness of the Zn-20Sn-0.5RE solder is lower than that of the Zn-20Sn solder. Figure 6 shows that the displacement increases nonlinearly with loading. For $120 \mathrm{~s}$ with a maximum load of $6 \mathrm{mN}$, platforms with different lengths appear in various curves. During this process, the displacement deepens with time. At this time, creep occurs in each phase.

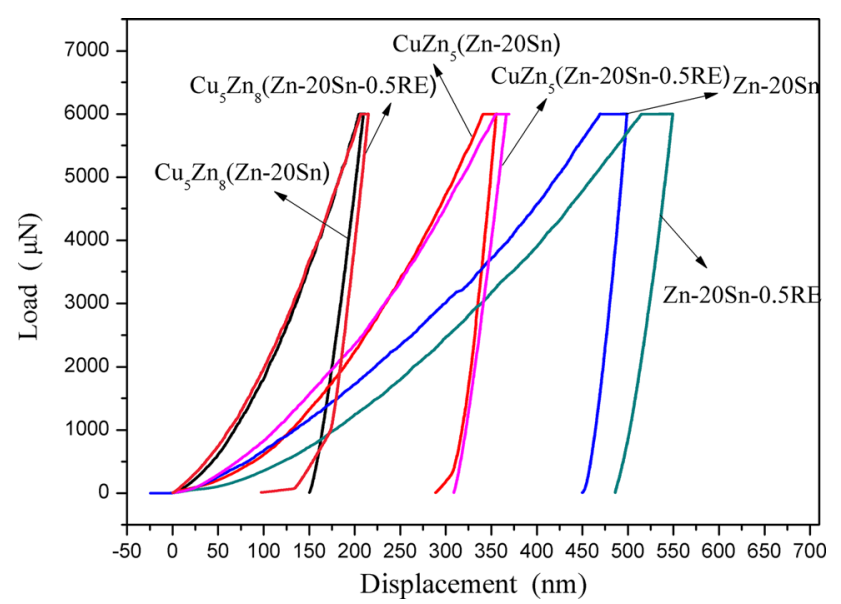

Fig. 6. Load-displacement curves of each phase at the interface.

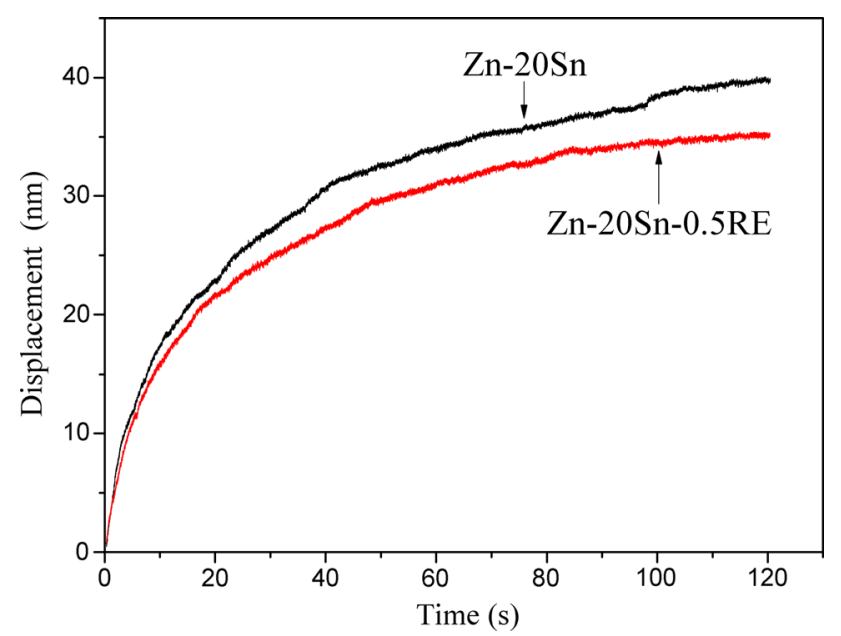

Fig. 7. Creep displacement-creep time curves for solders.

The creep displacement-creep time curves of the solders at maximum load are shown in Fig. 7. The curves can be divided into two stages: the initial stage and the large displacement stages. In the initial stage, the creep displacement increased rapidly, and then slowly increased with time. At large displacement stage, the creep displacement and creep time exhibit an approximate linear relationship. When the maximum load is maintained, the $\mathrm{Zn}$-20Sn-0.5RE solder has a smaller creep displacement than that of Zn-20Sn solder, and its creep resistance is better. After adding $0.5 \mathrm{wt} . \%$ $\mathrm{RE}$, some of REs segregate in the surface or at the solid-liquid interface, which reduces the interfacial tension. Some of REs exist as RE-Zn compounds. ${ }^{8}$ Stable compounds are distributed in the slip surface, which hinders dislocation movement and improves the solder creep property.

The elastic modulus, hardness and other properties of each phase are shown in Table II. With the transition from solder matrix to interfacial compound, the hardness increases gradually. The 
Table II. Data of nano-indentation of solder joints for each phase

\begin{tabular}{|c|c|c|c|}
\hline Name of the phase & Elastic modulus $E$ (GPa) & Hardness $H$ (GPa) & $\boldsymbol{E} / \boldsymbol{H}$ \\
\hline Zn-20Sn & $65.01 \pm 8.84$ & $1.00 \pm 0.34$ & 65.0 \\
\hline $\mathrm{CuZn}_{5}(\mathrm{Zn}-20 \mathrm{Sn})$ & $71.10 \pm 10.96$ & $2.16 \pm 0.36$ & 32.9 \\
\hline $\mathrm{Cu}_{5} \mathrm{Zn}_{8}(\mathrm{Zn}-20 \mathrm{Sn})$ & $107.14 \pm 2.43$ & $5.45 \pm 0.31$ & 19.7 \\
\hline $\mathrm{Zn}-20 \mathrm{Sn}-0.5 \mathrm{RE}$ & $42.28 \pm 1.26$ & $0.83 \pm 0.10$ & 50.9 \\
\hline $\mathrm{CuZn}_{5}(\mathrm{Zn}-20 \mathrm{Sn}-0.5 \mathrm{RE})$ & $62.26 \pm 3.52$ & $1.89 \pm 0.10$ & 32.9 \\
\hline $\mathrm{Cu}_{5} \mathrm{Zn}_{8}(\mathrm{Zn}-20 \mathrm{Sn}-0.5 \mathrm{RE})$ & $117.09 \pm 2.14$ & $5.18 \pm 0.33$ & 22.6 \\
\hline
\end{tabular}

elastic modulus and indentation hardness of solder is the smallest, followed by $\varepsilon-\mathrm{CuZn}_{5}$, and the $\gamma$ $\mathrm{Cu}_{5} \mathrm{Zn}_{8}$ is the largest. The $\gamma-\mathrm{Cu}_{5} \mathrm{Zn}_{8}$ layer has large thickness and high hardness, which becomes a brittle phase in the solder joint.

With an increase in $E / H$, the relative elastic recovery becomes less, hence resulting in a greater degree of plastic deformation. ${ }^{19}$ Based on this concept, the $E / H$ values of these phase of the interface were calculated and are listed in Table II. The ability for plasticity of these phase in decreasing order was: Zn-20Sn, Zn-20Sn-0.5RE, $\mathrm{CuZn}_{5}$, $\mathrm{Cu}_{5} \mathrm{Zn}_{8}$.

The elastic modulus of the IMC CuZn 5 (Zn-20Sn) is $9 \%$ greater than that of the $\mathrm{Zn}-20 \mathrm{Sn}$ solder. The elastic modulus of the $\mathrm{Cu}_{5} \mathrm{Zn}_{8}$ (Zn-20Sn) is $64 \%$ greater than that of the $\mathrm{Zn}-20 \mathrm{Sn}$ solder. The elastic modulus on both sides of the $\mathrm{CuZn}_{5} / \mathrm{Cu}_{5} \mathrm{Zn}_{8}$ interface has changed abruptly, and has become a weak area of solder joint. From the micro zone mechanical properties, it can be explained that the fracture location of the soldered joints of the $\mathrm{Zn}-20 \mathrm{Sn} / \mathrm{Cu}$ is at the $\mathrm{CuZn}{ }_{5} / \mathrm{Cu}_{5} \mathrm{Zn}_{8}$ interface. ${ }^{2}$

\section{CONCLUSIONS}

1. The addition of RE has almost no effect on the wetting time at temperature of $410-440^{\circ} \mathrm{C}$. The corrosion resistance of the $\mathrm{Zn}-20 \mathrm{Sn}-0.5 \mathrm{RE}$ solder is improved.

2. $\mathrm{RE}$ addition increases thickness of the $\varepsilon-\mathrm{CuZn}_{5}$ and $\gamma-\mathrm{Cu}_{5} \mathrm{Zn}_{8}$ layer at the soldering interface, promotes bamboo-shoot-like growth of the $\varepsilon$ $\mathrm{CuZn}_{5}$, increases the roughness of the $\varepsilon-\mathrm{CuZn}_{5}$ layer at the interface, and improves the shear strength of the soldered joints.

3. After soldering, the creep resistance of the $\mathrm{Zn}$ 20Sn-0.5RE solder is improved. With the transition from solder matrix to interfacial compound, the indentation hardness and elastic modulus increased gradually. The elastic modulus on both sides of the $\mathrm{CuZn}{ }_{5} / \mathrm{Cu}_{5} \mathrm{Zn}_{8}$ interface has changed abruptly, and becomes a weak area of soldered joint.

\section{ACKNOWLEDGMENTS}

This work was supported by the scientific and technological project in Fujian Province (2015H0008).

\section{REFERENCES}

1. S. Menon, E. George, M. Osterman, and M. Pecht, J. Mater. Sci. Mater. Electron. 26, 4021 (2015).

2. J.E. Lee, K.S. Kim, K. Suganuma, J. Takenaka, and K. Hagio, Mater. Trans. 46, 2413 (2005).

3. S. Kim, K.S. Kim, K. Suganuma, and G. Izuta, J. Electron. Mater. 38, 873 (2009).

4. K. Suganuma, S.J. Kim, and K.S. Kim, JOM 61, 64 (2009).

5. W.L.R. Santos, C. Brito, J.M.V. Quaresma, J.E. Spinelli, and A. Garcia, Mater. Sci. Eng., B 182, 29 (2014).

6. C.W. Liu and K.L. Lin, J. Electron. Mater. 43, 4502 (2014).

7. C.M.T. Law, C.M.L. Wu, D.Q. Yu, L. Wang, and J.K.L. Lai, J. Electron. Mater. 35, 89 (2006).

8. J. Tian, P. Dai, and X. Li, J. Mater. Sci. Mater. Electron. 28, 17185 (2017).

9. D.Q. Yu and L. Wang, J. Alloys Compd. 458, 542 (2008).

10. M.K. Choi, C.Y. Lee, C.J. Shur, and J.P. Jung, J. Electron. Manuf. 8, 235 (1998).

11. F. Rosalbino, E. Angelini, D. Macciò, A. Saccone, and S. Delfino, Electrochim. Acta 52, 7107 (2007).

12. D. Ma, W.D. Wang, and S.K. Lahiri, J. Appl. Phys. 91, 3312 (2002).

13. J.K. Shang and D. Yao, J. Electron. Packag. 118, 170 (1996).

14. S. Kim, K.S. Kim, S.S. Kim, and K. Suganuma, J. Electron. Mater. 38, 266 (2009).

15. B. Lao, S. Gao, and Q. Zhang, Acta Phys. Chim. Sin. 17, 453 (2001).

16. X. Deng, N. Chawla, K.K. Chawla, and M. Koopman, Acta Mater. 52, 4291 (2004).

17. G.Y. Jang, J.W. Lee, and J.G. Duh, J. Electron. Mater. 33, 1103 (2004).

18. A.R. Geranmayeh and R. Mahmudi, J. Electron. Mater. 34, $1002(2005)$

19. J.M. Song, M.J. Lin, K.H. Hsieh, T.Y. Pai, Y.S. Lai, and Y.T. Chiu, J. Electron. Mater. 42, 2813 (2013). 